\title{
MEDIDAS PREVENTIVAS NA GESTÃO INTEGRADA DO RISCO DE INUNDAÇÃO EM PORTUGAL: O PLANEAMENTO PARTICIPATIVO E O PAPEL DAS COMUNIDADES LOCAIS
}

\author{
Francisco da Silva Costa \\ Departamento de Geografia e CEGOT, Instituto de Ciências Sociais da Universidade do Minho \\ costafs@geografia.uminho.pt \\ Luciano Lourenço \\ Departamento de Geografia e CEGOT, Faculdade de Letras da Universidade de Coimbra \\ luciano@uc.pt \\ Carmen Ferreira \\ Departamento de Geografia e CEGOT, Faculdade de Letras da Universidade do Porto \\ dra.carmenferreira@gmail.com \\ Maria Gouveia \\ Doutoranda, CEGOT, Faculdade de Letras da Universidade de Coimbra \\ mmalgouveia@gmail.com
}

\section{RESUMO}

A falta de políticas que promovam a gestão integrada de inundações em Portugal é uma realidade, sendo que o investimento de recursos financeiros é essencialmente concentrado na resolução das crises, em detrimento de medidas técnico-administrativas de prevenção. Neste contexto, destaca-se o planeamento participativo já que implica todos os interessados no desenvolvimento de políticas de gestão do risco de inundação e permite aos habitantes das regiões vulneráveis escolher o nível de risco que estão prontos para assumir. Com esta comunicação, pretende-se contribuir para a discussão do modelo de gestão do risco de inundações em Portugal, refletindo sobre a falta de planeamento participativo e da intervenção das comunidades locais, como ferramenta para a prevenção e enfrentamento de cenários de catástrofe.

Palavras-chave: Prevenção, Gestão integrada, Proteção civil.

\section{Introdução}

Foi, exatamente há um século, nos começos do Inverno de 1909, que no rio Douro se verificou uma das maiores cheias de sempre. O Boletim da Associação Comercial do Porto daquele mês chamava a atenção dos seus associados que operavam na zona ribeirinha para o facto de as águas do Douro estarem a subir gradualmente. Dias mais tarde, o guarda municipal que ali fazia giro contactou os moradores, avisando-os de que deviam tomar precauções porque a cheia vinha a caminho (Jornal de Notícias online, 2014).

Um século depois, a Associação de Técnicos de Segurança e Proteção Civil (ASPROCIVIL) alertava para a necessidade de se tomarem medidas preventivas tendo emitido um comunicado em que afirmava que “....Não temos uma cultura de prevenção nem de planeamento, o ordenamento do território não é feito tendo em conta a tipologia de riscos...” (Público online, 2014).

A própria União Europeia, através da resolução do Parlamento Europeu sobre inundações de 3 de Julho de 2013, recomendou a aplicação dos programas de prevenção das inundações, através de medidas abrangentes, designadamente uma participação mais estreita das regiões, cidades e comunidades locais.

Falando da gestão de risco de inundação... Algumas pistas

A proteção absoluta de inundações é um mito. Existirão sempre alguns riscos residuais. É neste contexto que surge o conceito de "Risco aceitável" (UNISDR, 2009). Ora, o risco aceitável 
implica a necessidade de uma gestão integrada do risco de inundação, em vez de uma abordagem fragmentada, difícil de atingir onde as gestões municipais sofrem de falta de capacidade técnica, financiamento ou recursos.

Por isso, a gestão integrada do risco de inundação exige uma mudança de paradigma, de base proactiva, por forma a assegurar uma efetiva integração das preocupações de redução do risco nas políticas relacionadas com o desenvolvimento sustentável (Shrestha, 2008).

De facto, a redução do risco é uma das principais metas na gestão do risco de inundação e pode ser tratada através de estratégias de prevenção que alguns autores enquadram no âmbito da "cultura de prevenção" ou mesmo do "direito da prevenção das inundações" (Aragão, 2009; CEDOUA, 2007).

\section{O Planeamento participativo como processo para a prevenção do risco de inundação}

Atualmente, aceitamos que a gestão de inundações pode beneficiar muito com a participação dos envolvidos. Para esse feito, a ação de reduzir o risco de inundação deve ser elaborada por meio de um processo participativo, pelo que uma exigência fundamental passa por identificar as informações, experiências e métodos que diferentes atores podem fornecer, e, depois, projetar medidas concretas, usando tal experiência e conhecimento (APFM, 2006).

Por outro lado, também é importante estar consciente do contexto em que a gestão de risco de inundação opera, pois é essencial compreender as capacidades e incentivos dos atores e agentes implicados, inclusive o modo como eles alocam ou são capazes de usar os seus limitados recursos num quadro de futura incerteza (Sayers et al., 2013).

Frequentemente deparamo-nos com o argumento das dificuldades que as autoridades locais ou serviços de proteção civil referem as dificuldades no ato de planear ou intervir em áreas de risco de inundação. No entanto, outros argumentos devem ser ponderados:

- a possibilidade de limitar o perigo para a vida das pessoas e de proteger as suas propriedades enquadra-se na categoria de atividades de prevenção.

- a capacidade de responder corretamente a um fenómeno rápido depende do conhecimento e da consciência do risco, por parte dos moradores, usuários do terreno e serviços de proteção civil locais, o que requer planeamento e atividades educacionais.

- a eficácia na operacionalização das atividades desenvolvidas pelas comunidades locais requer uma análise cuidadosa por parte da proteção civil (APFM, 2007).

\section{A importância da comunidade local para a gestão de risco de inundação}

O envolvimento da comunidade é fundamental em todas as etapas da gestão do risco de inundação, incluindo a identificação de riscos, priorização, formulação de plano, implementação, monitorização e avaliação (Shrestha, Chapagain e Thapa, 2011).

Na preparação para a inundação, a maioria das instituições tende a favorecer um conhecimento científico especializado que, frequentemente, não pode ser assimilado em contextos e realidades locais, onde predomina o "conhecimento local" (Local Knowledge) com base na vivência e experiências das pessoas que lidam com as diferentes situações de risco (Jha, Bloch e Lemon, 2012).

Numa estrutura simples, que descreva a forma como o conhecimento local poderá estar relacionado com a preparação para uma catástrofe, devemos considerar a capacidade das pessoas para observarem o seu ambiente local, para identificarem e monitorarem indicadores ambientais (neste caso, de uma inundação iminente), para desenvolverem estratégias de 
adaptação para inundações recorrentes e para a compreensão das cheias passadas e das presentes (Shrestha, Chapagain e Thapa, 2011).

A gestão risco de inundação e proteção civil em Portugal - Problemas e desafios Portugal, ao assinar a Declaração de Hyogo comprometeu-se em desenvolver, uma cultura de prevenção para a mitigação dos riscos (EIRD/ONU, 2007) com base em abordagens inovadoras que contemplem, nomeadamente: o desenvolvimento de estratégias locais e comunitárias (GPDRR/UN, 2009).

À escala europeia, a adoção da Directiva 2007/60/CE, de 23 de Outubro de 2007, relativa à avaliação e gestão dos riscos de inundações veio assegurar um tratamento jurídico autónomo deste tipo de risco. Portugal apresenta no seu quadro legislativo nacional vários Decretos-Lei que versam sobre a temática das inundações, sendo de destacar o Decreto-Lei n 115/2010, de 22 de Outubro, que transpôs para o ordenamento jurídico nacional a Directiva referida anteriormente.

Pelo exposto, podemos afirmar que há, atualmente, um dever do Estado de prevenir riscos, resultante do Direito Europeu, e que esta obrigação está expressamente prevista para a prevenção e gestão de um risco específico, as inundações (Aragão, 2011).

De acordo com o Decreto-Lei n. ${ }^{\circ}$ 75/2007, de 29 de Março, a Autoridade Nacional de Proteção Civil é responsável pela segurança das populações e pela salvaguarda do patrimônio, com vista a prevenir acidentes graves e catástrofes. Embora a preocupação pela prevenção esteja expressa nos domínios sobre os quais a atividade da proteção civil deverá ser exercida, as políticas e as operações de proteção civil são praticamente omissas sobre o assunto, preocupando-se mais com medidas reativas que culminam com a criação dos Planos de Emergência (Zêzere, 2007). Sendo a proteção civil uma atividade que envolve todos os cidadãos, coletiva e individualmente considerados, levanta-se a interrogação de saber como se promove o exercício de uma cidadania ativa com capacidade participativa nas decisões e opções relativas às políticas a prosseguir neste domínio. Uma das formas de prevenção que parece mais adequada e mais eficaz para agir sobre as populações mais frágeis, passa por desenvolver a consciência cívica, difundindo técnicas de proteção civil, criando, na sociedade civil, capacidades de resistência onde elas não existiam e infletindo a tendência para a passividade e a inércia, resultantes da delegação no Estado de todas as responsabilidade relativas à proteção civil (Ribeiro, 2012).

\section{Conclusões}

A gestão do risco de inundação deve ser caracterizada como participativa, compartilhada, continuada e fortemente solidária, para a sua aplicação na comunidade, com o objetivo de melhorar o ambiente e o bem-estar do ser humano - algo que alguns autores referem como "hidrossolidariedade" (Blenkner, 2001; Falkenmark, 2002; Ribeiro, 2007).

Para o futuro, será vital ligar a gestão de risco de inundações com questões mais específicas do planeamento participativo, as comunidades locais e a gestão urbana. Soluções robustas podem contribuir para a redução de risco de inundações, enquanto, ao mesmo tempo, criam oportunidades de promover um desenvolvimento mais sustentável e resiliente.

\section{Bibliografia}

APFM (2007) - Guidance on Flash Flood Management. Recent Experiences from Central and Eastern Europe. Associated Programme on Flood Management, Genebra, 66 p. 
APFM (2006) - Legal and Institutional Aspects of Integrated Flood Management. Flood management policy series, WMO-No. 997, Associated Programme on Flood Management, Genebra, 103 p.

Aragão, A. (2011) - Prevenção de riscos na União Europeia: o dever de tomar em consideração a vulnerabilidade social para uma protecção civil eficaz e justa. Revista Crítica de Ciências Sociais, 93, Junho 2011, p.71-93.

Aragão, A. (2009) - A prevenção de riscos em Estados de direito ambiental na União Europeia. Observatório do Risco, Centro de Estudos Sociais, Universidade de Coimbra. Coimbra, 39 p.

Blenkner, S. (2001) - Turning the page for Hydrosolidarity in Spain: Inherited paradigms favor Well-off framees. Stockholm International Water Institute. Report Series. Report 13, Stockholm.

CEDOUA (2007) - O risco de inundação em Portugal. Dossier. Revista do Centro de Estudos de Direito do Ordenamento, do Urbanismo e do Ambiente, 2.2007, Coimbra, p. 167-179.

Decreto-Lei n. ${ }^{\circ}$ 75/2007. D.R. n. ${ }^{\circ}$ 63, Série I de 2007-03-29. Ministério da Administração Interna.

EIRD/ONU (2007) - Marco de Ação de Hyogo 2005-2015: Aumento da resiliência das nações e das comunidades frente aos desastres. Estratégia Internacional para Redução de Desastres/Organizações das Nações Unidas. Protocolo disponível: http://www.integracao.gov.br/cidadesresilientes/pdf/mah_ptb_brochura.pdf [12 jul. 2014].

Falkenmark, M. (2002) - Socio-hydroecologic catchement Management - Towards Hydrosolidarity. Stockholm International Water Institute, Stockholm.

GPDRR/UN (2009) - Proceedings Creating Linkages for a Safer Tomorrow, Global Platform for Disaster Risk Reduction, 2nd session, United Nations International Strategy for Disaster Reduction, Geneve, $44 \mathrm{p}$.

Jha, K. A., Bloch, R., Lemon, J. (2012) - Cities and Flooding. A Guide to Integrated Urban Flood Risk Management for the 21st Century. Global Facility for Desaster Reduction and Recovery, International Bank for Reconstruction and Development, Washington DC, 638 p.

Jornal de Notícias (online) de 27 de dezembro de 2009, acedido em 17 de julho 2014.

Jornal Oficial da União Europeia (2007) - Directiva 2007/60/CE do parlamento europeu e do conselho de 23 de Outubro de 2007 relativa à avaliação e gestão dos riscos de inundações. Parlamento Europeu e Comissão Europeia, Bruxelas, p. 27-34.

Parlamento Europeu (2013) - Resolução do Parlamento Europeu, de 3 de julho de 2013, sobre as inundações na Europa (2013/2683 (RSP)).

Público (online) de 24 de outubro de 2013, acedido em 27 de julho de 2014.

Ribeiro, C. A. G. R. (2007) - Hidrossolidariedade como princípio de gestão participativa de risco de inundações por associação de bacia. Dissertação apresentada à Universidade de São Paulo-Escola de Engenharia de São Carlos-Centro de Recursos Hídricos e Ecologia Aplicada, Programa de pós-graduação das ciências da engenharia ambiental, São Paulo, 212 p.

Ribeiro, M. J. (2012) - Proteção Civil. Revista Atena № 28, Imprensa Nacional Casa da Moeda, Lisboa, p. 109-119. Sayers, Y. L.i, G. Galloway, E. Penning-Rowsell, F. Shen, K. Wen, Y. Chen, and T. Le Quesne (2013) - Flood Risk Management: A Strategic Approach. Paris, UNESCO, 202 p.

Shrestha, A. B. (2008) Resource Manual on Flash Flood Risk Management. Module 2: Non-structural Measures. International Centre for Integrated Mountain Development, Kathmandu, 103 p.

Shrestha, A. B., Chapagain, P. S, e Thapa, R. (2011) - Flash Flood Risk Management. A Training of Trainers Manual. International Centre for Integrated Mountain Development, Kathmandu, $160 \mathrm{p}$.

UNISDR (2009) - Terminology on Disaster Risk Reduction. United Nations International Strategy for Disaster Reduction, Geneva, 35 p.

Zêzere, J. L. (2007) - "Riscos e ordenamento do território", Inforgeo 20/21, Ordenamento territorial, Associação Portuguesa de Geográfos, Lisboa, p. 59-63. 